\title{
Reversible anterior cord syndrome due to penetration of the spinal canal by pedicular screws
}

\author{
S Yalçın ${ }^{1}$ and O Güven ${ }^{2}$ \\ ${ }^{1}$ Assistant Professor, ${ }^{2}$ Professor, Marmara University School of Medicine Department of Orthopedics and \\ Traumatology, Istanbul, Turkey
}

The use of transpedicular screws in patients with disturbed posterior column anatomy is sometimes hazardous. We report a patient with a burst fracture at T7 who developed an anterior cord syndrome immediately after posterior instrumentation. Diagnosis of the anterior cord syndrome was ascertained by an emergency computerised tomogram which showed a misplaced screw compressing the cord from the anterolateral aspect of the spinal canal. Extraction of this screw and revision of the instrumentation resulted in speedy and complete resolution of the neurological deficit. The patient was mobilised within the first postoperative week and was able to work by the fourth postoperative month. The application of smooth contoured screws and blunt surgical instruments was found to be helpful because they are less likely to produce a cutting injury of neural tissue. We must further stress that transpedicular screws for the upper thoracic segments are to be employed very cautiously, if ever, to avoid severe neurological complications.

Keywords: anterior cord syndrome; spinal instrumentation; pedicular screw; complications

\section{Introduction}

In recent years there has been progress in the surgical treatment of deformities and of unstable lesions of the thoracolumbar spine. A multitude of posterior fixation systems employing variations of hooks, screws and sublaminar wires combined with rods or plates for posterior or anterior instrumentation have been developed. Among these the pedicular screw has several obvious advantages over other available spinal fixation instruments. The tubular pedicle consists of dense cortical bone and is relatively safe from osteoporosis even in senile, paralytic or bed-ridden patients. These properties make the pedicle the site of choice for instrumentation. ${ }^{1}$ However there is an important drawback: the risk of iatrogenic nerve injury by improper screw insertion. A misplaced screw can impair a nerve root or the spinal cord by either compression or by a direct cutting injury. The application of transpedicular screws may be particularly dangerous at the upper thoracic segments.

\section{Case report}

A 27-year-old male patient with a burst fracture at $\mathrm{T} 7$ vertebral level, and posterior column disruption of the neighbouring segments, without any concomitant neurological injury was operated with Cotrel-Dubousset instrumentation. Posterior stabilisation and reduction of the fracture was performed as an emergency procedure. Pedicular screws were inserted at T5, T6, T8 and T9 to accomplish

Correspondence: S Yalçın, PK. 21 Koşuyolu, Istanbul 81021, Turkey the reduction and stabilisation of the complex fracture. Difficulties were encountered in screw orientation because of the disturbed anatomy of the posterior structures. Fluoroscopic studies employed intraoperatively showed satisfactory screw positioning. Peroperative SEP monitorisation could not be employed because of the urgency of the operation. In the recovery room the patient was found to have complete motor loss of both lower extremities with deep sensory sparing. The bulbocavernous reflex was positive. Immediate computerised tomography (CT) studies revealed canal encroachment by a screw at T8 level (Figure 1). This screw crossed the canal almost at its greatest

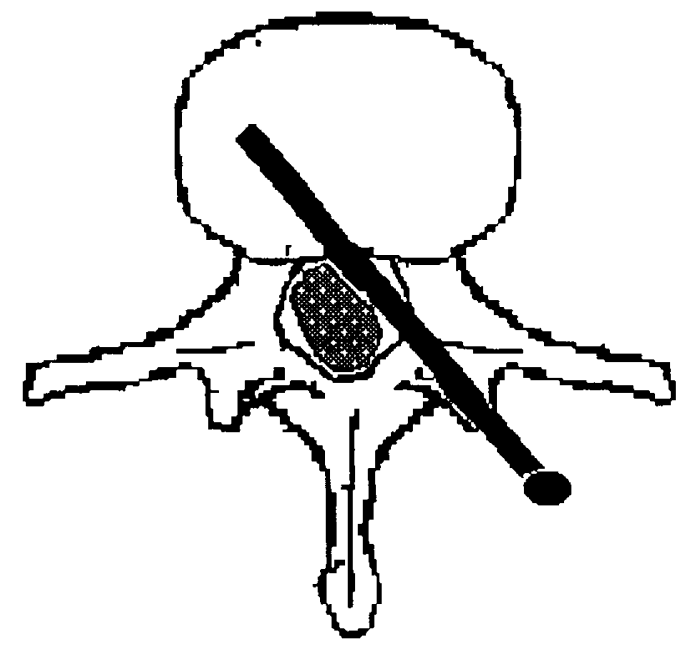

Figure 1 Schematic drawing representing the coronal view. The cord is compressed by the screw from the anterolateral aspect of the canal 
diameter. The definitive diagnosis of an iatrogenic anterior cord syndrome was ascertained. Emergency surgery to remove the misplaced screw and revise the instrumentation was initiated within $2 \mathrm{~h}$ of the conclusion of the first operation. The compression of the spinal cord was relieved by extraction of all of the screws and excision of the lamina of T8. The duramater was found to be ruptured by the screw at T8 level. Despite the significant extent of canal encroachment the neural tissue was not damaged macroscopically presumably due to the smooth, non-cutting contours of the employed screw. Long segment instrumentation at the adjacent levels was performed with hooks on T1, T2 and T3 and screws at T9 and T10. Immediately after recovery from the general anaesthesia the patient was found to have normal muscle strength and coordination. Wound healing was uneventful, and he was mobilised on the fourth day postoperatively wearing a thoracolumbosacral orthosis. On late follow-up there was complete wound healing with no neurological or musculoskeletal sequelae. He was able to return to work at the end of the fourth postoperative month.

\section{Discussion}

Pedicle screw systems provide significant and, in many cases, improved and previously unattainable spinal fixation. However, pedicle screw systems represent difficult surgical techniques involving several potential problems and complications. Only by detailed knowledge of the anatomy of the spine, with a clear understanding of the pedicle screw systems implementation, can the risk of complications be minimised. ${ }^{2}$

The morphometry of the pedicles of cervical, thoracic, lumbar and sacral pedicles have been described by Zindrick et $a l^{3}$ and others. ${ }^{4,5}$ These studies clearly show that there are substantial differences between pedicle orientations and diameters at different anatomical regions. These substantial changes in the sagittal and transverse orientation of the pedicle at different segments are to be respected by the surgeon.

A recent study on the surgical treatment of thoracolumbar fractures encompassing 641 pedicle fixation and 1129 hook-rod fixation cases revealed that there were no differences in the incidence of perioperative neurological complications. ${ }^{6}$ The severity of neural lesions was not noted in this study but we can postulate that the neurological injury produced by a misplaced pedicle screw will very probably produce a worse outcome than would a mishap with a hook-rod system. Particularly in the upper thoracic vertebrae the confinement of the narrow pedicle diameter and the lack of relatively free space in the spinal canal render the application of screws dangerous. Zindrick et al's studies, ${ }^{3}$ performed early in 1986, well before the popularisation of transpedicular screw fixation, have revealed that the chief anatomical delimination to transpedicular fixation is imposed by the transverse pedicle isthmus, whose mean width approaches $5 \mathrm{~mm}$ at T6, and is even narrower at T5 (Table 1). The spine surgeon must also always appreciate that in some cases this isthmus may be as narrow as $3 \mathrm{~mm}$ or less between T2 and T12 as seen on Table 1. Since CD and most other spinal instrumentation systems are utilising screws of $5 \mathrm{~mm}$ diameter for
Table 1 Transverse pedicle isthmus width in $\mathrm{mm}$ as indicated by the study of Zindrick et al $^{3}$

\begin{tabular}{lccccc}
\hline Level & $N$ & Mean & Range & $S D$ & $S E M$ \\
\hline L5 & 56 & 18 & $9.1-29.0$ & 4.1 & 0.5 \\
L4 & 36 & 12.9 & $9.1-17.0$ & 2.1 & 0.4 \\
L3 & 49 & 10.3 & $5.3-16.0$ & 2.6 & 0.4 \\
L2 & 30 & 8.9 & $4.0-13.0$ & 2.2 & 0.4 \\
L1 & 26 & 8.7 & $4.5-13.0$ & 2.3 & 0.5 \\
T12 & 36 & 7.1 & $3.0-11.0$ & 2.3 & 0.4 \\
T11 & 27 & 7.8 & $3.1-12.0$ & 2 & 0.4 \\
T10 & 24 & 6.3 & $3.1-8.5$ & 1.7 & 0.3 \\
T9 & 27 & 6.1 & $3.7-9.0$ & 1.5 & 0.3 \\
T8 & 41 & 5.9 & $2.5-9.0$ & 1.6 & 0.3 \\
T7 & 32 & 5.3 & $3.2-7.0$ & 1 & 0.2 \\
T6 & 33 & 5.2 & $3.0-6.5$ & 1 & 0.2 \\
T5 & 34 & 4.5 & $3.0-7.0$ & 0.9 & 0.2 \\
T4 & 25 & 4.7 & $2.5-7.0$ & 1.3 & 0.3 \\
T3 & 27 & 5.6 & $3.0-8.5$ & 1.4 & 0.3 \\
T2 & 24 & 7 & $3.5-10.0$ & 1.8 & 0.4 \\
T1 & 24 & 7.9 & $5.0-10.0$ & 1.4 & 0.3 \\
\hline
\end{tabular}

thoracic fixation, the responsibility lies on the acting surgeon whether or not to use screws for the thoracic vertebrae. ${ }^{7}$

As clearly seen in Table 1 in the lower lumbar spine the pedicles are wide enough and there is a further safe zone for misplaced screws in the spinal canal around the cauda equina. Whereas even in experienced hands upper thoracic screws are liable to produce complications, particularly in patients with disturbed posterior element anatomy which is the major determinant for accurate screw orientation.

In the present patient early intervention by screw extraction has produced a very good clinical result, with immediate complete neurological recovery, despite the usual poor prognosis for the anterior cord syndrome. Usually patients with an anterior cord syndrome have only a $10 \%-20 \%$ chance of obtaining any functional recovery, and even in those with some recovery there remains very little functional muscle power and coordination. ${ }^{8}$ Our patient with immediate complete recovery was a very rare exception. The denomination of this complication as 'reversible anterior cord syndrome' is debatable but the typical clinical findings and the location of the injury make such a definition acceptable. We can postulate that this patient would eventually obtain the complete form of the syndrome if he was not treated very early.

The importance of proper screw placement to avoid neurological complications is obvious, but there will always be patients in which the anatomical landmarks for screw insertion and orientation will be obscured. (eg fracture, revision surgery, congenital anomalies, etc). Although there are established techniques aiding the surgeon to orient the screws properly, a small percentage of the screws are apt to miss the ideal position even in non-complicated cases. Some recent publications have shown that the screw misplacement rate with or without neurological damage is still high. ${ }^{9-11}$ Multiple methods were described for the 
intraoperative determination of the screw entrance point ${ }^{12,13}$ and the direction of the screw. ${ }^{7,13}$ Routine radiological or radioscopic examination is not always adequate in evaluating the screw position. ${ }^{11}$ The employment of intraoperative radiological monitoring for each step of the operation is time consuming and its results are not always reliable. $\mathrm{Krag}^{1}$ has recently published a report of a new method of intraoperative radioscopic monitoring whose dependability is as yet unproven. In patients where screw orientation is doubtful, longer segment instrumentation of the adjacent vertebra may be a better alternative to risking the nerve root or the cord.

Another helpful method, that of the intraoperative and postoperative use of somatosensory evoked potentials to evaluate iatrogenic spinal dysfunction, has become the standard in many spinal surgery centres, but its employment on an emergency basis is difficult. ${ }^{14}$

Currently postoperative CT examination provides the best obtainable information regarding the position of the transpedicular screw in vivo, although the interference of metal can produce a blurred image. ${ }^{10,15}$ As was also clearly seen in our patient, CT evaluation can provide valuable data concerning the location of the screws.

Early diagnosis and revision of the fixation may be helpful in operative patients with an acute neurological deficit where smooth contoured screws and instruments do not cut into the nerve but only produce compression whose effects are mostly reversible in the early phase. The benefits of blunt instruments for pedicular instrumentation are clear although some authors prefer to use hand drills ${ }^{16-18}$ or power driven smooth wires ${ }^{19,20}$ which have the distinct disadvantage of producing neural injury if there is misplacement.

\section{Conclusions}

1 Blunt tipped, low profile, B type-threaded pedicular screws (for example: the CD screw) and blunt instruments should be preferred because they are less likely to cause harm to neural tissue in the case of screw misplacement into the spinal canal.

2 In patients with posterior vertebral column disruption, instrumentation of the fractured vertebrae should be avoided and longer segment fixation with screws for the adjacent intact vertebrae is preferred.

\section{References}

$1 \mathrm{Krag}$ M. Biomechanics of thoracolumbar fixation. A review. Spine 1991; 16S: 84-89.

2 Weinstein JN, Rydevik BL, Rauschning W. Anatomic and technical considerations of pedicle screw fixation. Clin Orthop 1992; 284: 34-46.

3 Zindrick MR et al. Analysis of the morphometric characteristics of the thoracic and lumbar pedicles. Spine 1987; 12: 160-165.

4 Olsewski JM et al. Morphometry of the lumbar spine: anatomical perspectives related to transpedicular fixation. $J$ Bone $J$ Surg Am 1990; 72: 541-550.

$5 \mathrm{Krag}$ MK et al. An internal fixator for posterior application to short segments of the thoracic, lumbar or lumbosacral spine. Clin Orthorp 1986; 203: 75-98.

6 Dickman CA, Yahiro MA, Lu HTC, Melkerson MN. Surgical treatment alternatives for fixation of unstable fractures of the thoracic and lumbar spine. A meta-analysis. Spine 1994; 15: 2266S-2273S.

7 Güven O, Esemenli T, Yalçın S, Karahan M. Transpedicular fixation in the treatment of various spinal disorders. Acta Chir Belg 1993; 93: 188-192.

8 Bohlman HH, Ducker TB. Spine and spinal cord injuries. In Rothman RH (ed). The Spine. 3rd edn. WB Saunders: Philadelphia, 1992, pp 973-1011.

9 Saillant G. Etude anatomique des pedicules vertebraux: Application chirurgicale. Rev Chir Orthop 1976; 62: 151-160.

10 Gertzbein SD, Robbins ES. Accuracy of pedicular screw placement in vivo. Spine 1990; 15: 11-14.

11 Weinstein JN, Spratt KF, Spengler D, Brick C. Spinal pedicle fixation: reliability and validity of roentgenogram-based assessment and surgical factors on successful screw replacement Spine 1988; 13: 1012-1018.

12 Dick W. The fixateur interne as a versatile implant for spine surgery. Spine 1987; 12: 882-900.

13 Esses SI, Bednar DA. Posterior pedicular screw techniques. In: Errico TJ, Waugh T, Bauer RD (eds). Spinal Trauma. JB Lippincott; Philadelphia, 1992, pp 301-308.

14 Güven O, Yalçın S, Karahan M, Us Ö. Root injuries due to transpedicular screw application and the role of DSEP. Presented at the XI. Meeting of Groupe International CoutrelDubousset, Lyon, France, 1994.

15 Güven O, Yalçın S, Karaham M, Sevinç T. Evaluation of transpedicular screws with computerized tomography. Orthop Rev 1994; 23: 511-516.

16 Andrews TA, Brooks S, Piggot H. Long term follow-up, evaluation of screw and graft fusion of the spine. Clin Orthop 1986; 203: 113-119.

17 Kinnard $\mathrm{P}$ et al. Roy-Camille plates in unstable spinal conditions: A preliminary report. Spine 1986; 11: 131-135.

18 Magerl F. Stabilization of the lower thoracic and lumbar spine with external skeletal fixation. Clin Orthop 1984; 189: 125-141.

19 Aebi M, Etter C, Kehl T, Thalgott J. The internal skeletal fixation system: A new treatment of thoracolumbar fractures and other spinal disorders. Clin Orthop 1988; 227: 30-43.

20 Dick $\mathrm{W}$ et al. A new device for internal fixation of thoracolumbar and lumbar spine fractures: The 'fixateur interne'. Paraplegia 1985; 23: 225-232. 